\title{
Entre os apitos do campo e da fábrica: o futebol à moda Bangu/Rio de Janeiro (1904-1929)
}

\section{Between the fields of the field and the factory: football in style bangu / Rio de Janeiro (1904-1929)}

\section{Entre los campos del campo y la fábrica: fútbol al estilo Bangu / Rio de Janeiro (1904-1929)}

\author{
iD (9) Nei Jorge dos Santos Junior \\ Facculdade Unilagos, Rio de Janeiro, Rio de Janeiro, Brasil \\ edfnei@hotmail.com
}

\begin{abstract}
Resumo: Este trabalho tem como objetivo discutir as peculiaridades do processo de organização do Bangu Athletic Club e o seu progressivo e dependente relacionamento com a Companhia Progresso Industrial do Brasil, entre os anos de 1904 a 1929. Quanto ao recorte temporal (19041929), levamos em conta as transformações ocorridas em Bangu ao longo desse período, em 1904 a fundação do Bangu Athletic Club, e em 1929 a fábrica passou por um retalhamento de suas terras, em que, consequentemente, emergiu o bairro Bangu, agora sem ligação direta com a fábrica. Como fontes, foram utilizados revistas e jornais consultados na Hemeroteca Digital da Biblioteca Nacional, além de pedidos de licenciamento e estatutos.
\end{abstract}

Palavras-chave: Bangu. Fábrica. Futebol.

\begin{abstract}
This paper aims to discuss the peculiarities about the organization process of Bangu Athletic Club and its progressive and dependent relationship with Companhia Progresso Industrial do Brasil, between the years 1904 to 1929. Regarding the time frame (1904-1929), we take into account the transformations that took place in Bangu throughout that
\end{abstract}


period, in 1904, the foundation of the Bangu Athletic club, and 1929, the year in which the factory underwent a shredding of its lands, in which consequently the Bangu neighborhood, now emerged, without direct connection with the factory. As sources were used magazines and newspapers consulted in the Digital Library of the National Library, licensing requests and statutes.

Keywords: Bangu. Factory. Football.

Resumen: Este artículo tiene como objetivo discutir las peculiaridades del proceso de organización del Bangu Athletic Club y su relación progresiva y dependiente con la Companhia Progresso Industrial do Brasil, entre los años 1904 a 1929. En cuanto al marco temporal (1904-1929), tenemos en cuenta las transformaciones que se produjeron en Bangu durante ese período, en 1904, fundación del club Bangu Athletic, y 1929, año en el que la fábrica sufrió un desmembramiento de sus tierras, en el que surgió como consecuencia el barrio de Bangu, ahora sin conexión directa con la fábrica. Como fuentes se utilizaron revistas y periódicos consultados en la Biblioteca Digital de la Biblioteca Nacional, solicitudes de licencias y estatutos.

Palabras clave: Bangu. Fábrica. Fútbol.

Submetido em: 27-10-2020

Aceito em: 26-04-2021 
Entre os apitos do campo e da fábrica: o futebol à moda Bangu/Rio de Janeiro (1904-1929) Nei Jorge dos Santos Junior

\section{Introdução}

O leitor mais atento que circula pelos bairros da cidade do Rio de Janeiro, pode estar se perguntando: quem nunca ouviu a expressão à moda Bangu? Certamente, um número expressivo da população carioca já ouviu ou reproduziu a famosa expressão. Na verdade, a locução adverbial de modo - à moda Bangu - cotidianamente presente na linguagem popular e, em particular, relacionada ao futebol, expressa de certa forma a multiplicidade do bairro suburbano: sem compromisso, amador ou de qualquer jeito. Isto é, vamos fazer como se faz em Bangu.

De fato, os indicadores da locução citada são traços que explicitam não só o processo de estratificação socioespacial da cidade carioca, como também os primórdios do futebol. Isso porque, na transição dos séculos XIX e XX, a prática foi marcada por interesses e representações que relacionavam o esporte inglês à formação de um novo modelo de cidadão (SANTOS JUNIOR, 2013).

Ainda que discursivamente, o futebol consistia em mais uma forma de celebração da alta sociedade carioca, expressada pelos valores do cavalheirismo, do fair play e do amadorismo. Esses elementos, considerados indispensáveis para um quadro social que incorporava o modelo europeu como parâmetro cultural, davam ao futebol um espaço privilegiado nos clubes, nas escolas e, principalmente, nas agendas de entretenimento das famílias mais abastadas da Capital (SANTOS JUNIOR, 2012; SANTOS JUNIOR, 2013).

Contudo, o processo de consolidação do velho esporte bretão não foi somente uma obra das elites, mas sim um constructo em que as classes populares também participaram intensamente. Concomitantemente, agrupados em centros esportivos formados nos subúrbios ou em seus locais de trabalho, como nas fábricas da Zona Sul (Laranjeiras e Jardim Botânico, por exemplo), trabalhadores, negros e migrantes também vivenciavam o jogo, fazendo dele um importante meio de expressão de seus desejos sociais específicos (SANTOS JUNIOR; MELO, 2013). Como destaca Souza (2015, p. 
Entre os apitos do campo e da fábrica: o futebol à moda Bangu/Rio de Janeiro (1904-1929) Nei Jorge dos Santos Junior

2), "o futebol chegou ao Brasil como parte de uma cultura proletária inglesa que foi abraçada tanto pelas elites quanto pelas classes baixas, mas de formas distintas e de acordo com as necessidades e possibilidades de cada grupo". Certamente, a fundação de vários clubes oriundos dos subúrbios, assim como a existência da Liga de Futebol no Rio de Janeiro, em 1906, e das Ligas Alternativas, em 1907, são exemplos disso (SOUZA, 2015).

Dessa forma, a fundação do próprio Bangu A. C., por exemplo, marcou a difusão da prática e o acesso mais direto ao futebol entre as camadas populares, pois contrariava o discurso de refinamento e fidalguia construído pelos primeiros sportsmen cariocas. Em outras palavras, a sua presença entre os clubes mais elitizados configurava a força do futebol nos círculos populares, tornando-se cada vez mais patente a participação de múltiplos estratos sociais que, assim, promoviam um alargamento simbólico nos sentidos do jogo (SANTOS JUNIOR; MELO, 2013).

No entanto, ainda que o futebol suburbano tenha papel fundamental no processo de apropriações e ressignificações da prática, tornando-o um grande fenômeno de massas, são poucos os debates que recorrem à clareza do objeto além da área central urbana. Grande parte dessa produção trilha por uma noção particular de lugar, desconsiderando o contraste e a complexidade que marcaram o futebol na cidade do Rio de Janeiro no início do século $X X$. Por conseguinte, as múltiplas possibilidades de análise sobre a inserção da prática nesses espaços são preteridas.

Isso significa que há uma escassez de estudos que se dedicam a um olhar mais plural sobre o futebol carioca. Esse número ainda pouco expressivo é reflexo de um olhar exíguo de cidade, em que o fenômeno deixar de ser compreendido a partir da complexidade e pluralidade. Ao fazê-lo, o olhar torna-se míope, subjugam espaços periféricos, entre eles os subúrbios, a um status de coadjuvante, ignorando a multiplicidade de práticas existentes nessas regiões.

Por isso, acreditamos que a formação do futebol carioca não pode ser pensada desarticulada das ações sociais dos subúrbios, 
Entre os apitos do campo e da fábrica: o futebol à moda Bangu/Rio de Janeiro (1904-1929) Nei Jorge dos Santos Junior

tampouco podemos entendê-la ignorando a sua história, pois a sua condição histórico-concreta sujeita-se à conjectura de diversas faces da sociabilidade de um local ao longo de um determinado período (LEFEBVRE, 1975).

Tendo em conta as motivações desse debate inicial, neste estudo pretendemos nos debruçar sobre as experiências do futebol em um bairro suburbano: Bangu. O objetivo é discutir as peculiaridades do processo de organização do Bangu Athletic Club e o seu progressivo e dependente relacionamento com a Companhia Progresso Industrial do Brasil, entre os anos de 1904, quando foi fundado o Bangu Athletic Club, e 1929, data na qual a fábrica passou por um retalhamento de suas terras, em que, consequentemente, emergiu o bairro Bangu, agora sem ligação direta com a fábrica. Para alcançar o objetivo, foram utilizados como fontes revistas e jornais consultados na Hemeroteca Digital da Biblioteca Nacional, pedidos de licenciamento e estatutos. Acreditamos, portanto, que as experiências na consolidação de clubes suburbanos devem ser entendidas em sua complexidade.

\section{Um clube de fábrica ou da fábrica?}

A constituição do bairro Bangu sempre apresentou peculiaridades. A região, localizada na zona suburbana da cidade do Rio de Janeiro, fica numa distância aproximada de $31 \mathrm{~km}$ da zona central e teve como primeiro proprietário o negociante português Manoel de Barcelos Domingos.

Fundada em 1673, a fazenda Bangu tornou-se essencialmente produtiva. O local era basicamente rural, formado por fazendas que se dedicavam à produção de açúcar, aguardente e produtos que se destinavam à exportação pelo porto de Guaratiba, bem como ao mercado interno. No entanto, com a Proclamação da República, um novo fator veio alterar a condição exclusiva da agricultura da região: a construção de uma fábrica de tecidos. 
Entre os apitos do campo e da fábrica: o futebol à moda Bangu/Rio de Janeiro (1904-1929) Nei Jorge dos Santos Junior

Inaugurada em 1889, a Companhia de Progresso Industrial do Brasil, conhecida também como Fábrica Bangu, teve papel fundamental no desenvolvimento do bairro, já que levava o progresso e a modernização a um espaço ainda caracterizado pelo modo de vida das fazendas, transformando-o, rapidamente, de rural a urbano fabril. Inserida no contexto histórico da época, quando o Rio de Janeiro era palco de um surto industrial e os ventos da modernidade contagiavam o imaginário social do período, a Fábrica Bangu conferia ao empreendimento a ideia de algo grandioso. A própria utilização da palavra progresso no nome da Companhia expressa a enorme importância desse tema, juntamente com as ideias de civilização e modernidade, no Rio de Janeiro da Belle Époque. Assim, a Companhia de Progresso Industrial do Brasil dava seus primeiros passos para assumir o papel de destaque no cenário têxtil nacional.

Ademais, outra característica fazia do bairro um lugar distinto das demais áreas dos subúrbios cariocas. Bangu era habitado em sua maioria por trabalhadores da fábrica, fazendo com que a vida das famílias e dos próprios trabalhadores, mesmo fora das horas de trabalho, continuasse ligada à empresa por meio das atividades de lazer e dos benefícios sociais garantidos (SANTOS JUNIOR, 2017).

A região, outrora rural, ficava situada na freguesia de Campo Grande, uma das 21 freguesias que compunham a Capital Federal. Em 1895, o bairro contava com cerca de mil habitantes, sendo possível apontar um grande número de estrangeiros. Destes, faziam parte cinquenta famílias italianas, cinquenta portuguesas, dez inglesas e dez de outras nacionalidades (SILVA, 1985). O restante dos moradores era composto por trabalhadores vindos de diferentes regiões da cidade ou do país, principalmente da área rural.

Seis anos depois, o bairro contava com cerca de 6.300 habitantes, o que representou $55 \%$ de crescimento referente ao dado anterior. Desse número, Santos Junior (2013) sustenta que 1.500 eram trabalhadores da Fábrica Bangu, o que mostra a importância 
Entre os apitos do campo e da fábrica: o futebol à moda Bangu/Rio de Janeiro (1904-1929) Nei Jorge dos Santos Junior

da indústria como centro econômico catalisador, instituindo, concomitantemente, um polo produtivo e um mercado consumidor.

Aliás, acreditamos que esses dados sejam importantes para compreendermos o impacto das ações da fábrica na região e na vida social dos seus habitantes, uma vez que as associações recreativas e esportivas mantinham ligação direta com a empresa, pela composição de seus associados, diretores e trabalhadores da fábrica, ou até mesmo pelo uso do espaço físico oferecido pela companhia (PEREIRA, 2006).

Não era de se estranhar, portanto, que alguns desses trabaIhadores, em sua maioria estrangeiros, quisessem a construção de um clube esportivo como tivera em seus países. Na Inglaterra, por exemplo, o epicentro do desenvolvimento esportivo mundial, o futebol já adotava a profissionalização desde 1885 , já tendo formada uma Liga em 1888, baseada no modelo do sistema estabelecido anteriormente nos Estados Unidos para o beisebol profissional (HOBSBAWM, 2008). Para Hobsbawm (2008), o esporte já se transformara em um dos temas prediletos dos populares, fazendo parte de uma cultura operária que tinha os pubs como locus importante de articulação. Em outras palavras, o futebol já se constituía tanto como uma forma de ligação entre trabalhadores de uma mesma cidade em torno de uma paixão quanto como um fomento para rivalidades entre comunidades de características diversas (HOBSBAWM, 2008).

Dessa forma, aos 17 dias de abril de 1904, na estação de Bangu, dez operários, entre eles, 8 ingleses, 1 português e 1 italiano, fundavam uma nova agremiação nos moldes daquelas que existiam em seus países: o Bangu Athletic Club ${ }^{1}$. Seus fundadores, todos trabalhadores da Companhia Progresso Industrial do Brasil, bem que tentavam desde 1897 organizar uma agremiação esportiva, mas alguns diretores da empresa não pareciam dispostos a apoiar tal iniciativa. Entre eles, o administrador da fábrica, o português Eduardo Gomes Ferreira, que alegava ser contra qualquer

1 Estavam presentes os seguintes srs.: John Stark, Fred. Jacques, Clarence Hibbs, Thomas Hellowell, José Soares, William Procter, William Hellowell, William French, Segundo Maffeu e Andrew Procter, formando um club athletic sob a denominação de "Bangu Athletic Club". Ver: Ata de Fundação, The Bangu Athletic Club, 1904. 
Entre os apitos do campo e da fábrica: o futebol à moda Bangu/Rio de Janeiro (1904-1929) Nei Jorge dos Santos Junior

tipo de jogo (MOLINARI, 2015). Os ingleses, porém, não esmoreceram e continuaram a pedir recursos para a fundação do clube.

Contudo, desdobramentos externos transformariam de vez as relações de lazer da região. Durante a greve geral de 1903, mesmo tendo a Fábrica Bangu participação pouco expressiva no movimento, curiosamente o diretor-gerente da Companhia, Eduardo Gomes Ferreira, pediu exoneração do cargo em 17 de agosto daquele ano, alegando problemas de saúde (MOLINARI, 2015). Na ocasião, o cargo acabou nas mãos do até então tesoureiro espanhol João Ferrer, que há tempos mantinha ligações estreitas com a cúpula da empresa.

Logo após a ascensão do espanhol ao cargo de administrador, as restrições em relação aos jogos chegariam ao fim, pois João Ferrer enxergava com bons olhos a criação de uma agremiação.

Rapidamente a notícia se espalhara por toda fábrica. Para compor o quadro de associados, sem qualquer distinção de cargos ou nacionalidade, bastava aos interessados darem seus nomes ao secretário Andrew Procter, responsável pela filiação (ATA FUNDAÇÃO..., 1904). Naquele momento formou-se um "club athletic sob a denominação de 'Bangu Athletic Club"', tendo "por fins os jogos de football, cricket, lawn tennis e outros jogos variados" (ATA FUNDAÇÃO..., 1904).

Diferentemente de outros clubes da cidade, nos quais o núcleo de ingleses convidava compatriotas para compor a equipe, no Bangu, até pelo isolamento geográfico do bairro, chefes, empregados e trabalhadores de outras nacionalidades integravam o time sem qualquer distinção, transformando a prática esportiva em uma das principais opções de lazer dos moradores da região (SANTOS JUNIOR, 2012; MELO; SANTOS JUNIOR, 2018). O próprio valor para associar-se ao clube já expressava a possibilidade de aceitação de trabalhadores das mais variadas origens: $2 \$ 000$ de joia e uma mensalidade de $1 \$ 000$, sendo que o salário dos operários variava de $94 \$ 800$ (no setor da fiação) até $260 \$ 640$ (no setor de acabamento) (ATA FUNDAÇÃO..., 1904; MALAIA, 2010). Isto é, 
Entre os apitos do campo e da fábrica: o futebol à moda Bangu/Rio de Janeiro (1904-1929) Nei Jorge dos Santos Junior

o clube, desde sua formação, já apresentava indicadores que pretendia agregar o maior número de funcionários possível, o que permitiu a difusão da prática e o acesso mais direto ao futebol entre as camadas populares.

Transformado em um modelo que seria, ao longo dos anos, adotado por muitos de seus pares, o Bangu Athletic Club estabelece uma ruptura no que tange à imagem de distinção social construída e desejada pelos sportsmen vinculados àqueles clubes frequentados pelas elites cariocas. A propósito, ser trabalhador da Companhia Progresso Industrial do Brasil era fator preponderante para tornar-se parte do quadro de associados do clube. Um bom exemplo desse ponto crucial está na convocação da assembleia do dia 24 de abril de 1904, sete dias após a fundação do clube, para tratar sobre os últimos detalhes da agremiação (ATA DA SESSÃO... 24 abr., 1904).

Após a leitura da ata, "adotada unanimemente por todos presentes", alguns pontos polêmicos tomariam a agenda do dia (ATA DA SESSÃO... 24 abr., 1904). O secretário Andrew Procter "propôs para sócios os seguintes operários, Srs. João da Silva, Bernardino Brito, Roldão Maia, César Bochialini, Onofre Lages, Gastão Bonfim, José Araújo e Antônio Bernardino, os quais foram aceitos, com exceção de César Bochialini", porque não sendo ele funcionário da fábrica, não poderia associar-se ao clube (ATA DA SESSÃO... 24 abr., 1904). Por conta disso, o primeiro assunto em pauta, apresentado pelo Sr. James Hartley, trazia, talvez, o elemento que simbolizaria significativamente essa relação: "para ser sócio do club é necessário ser empregado da Companhia" (ATA DA SESSÃO... 24 abr., 1904).

No entanto, é importante salientar que, mesmo com a negativa feita pelo Sr. Hartley, César Bochialini seria incorporado ao quadro de sócios em junho daquele mesmo ano (ATA DA SESSÃO... 24 abr., 1904). O italiano apareceria na ata de reunião de $1^{\circ}$ de junho de 1904, fazendo parte da equipe de solteiros para uma disputa de tug of war, uma espécie de cabo de guerra (ATA DA SESSÃO... 24 abr., 1904). Embora não tenhamos indícios precisos sobre a repen- 
Entre os apitos do campo e da fábrica: o futebol à moda Bangu/Rio de Janeiro (1904-1929) Nei Jorge dos Santos Junior

tina mudança de ideia, Molinari (2015) sugere que a entrada do pequeno comerciante local, dono de uma relojoaria para vendas e consertos no Marco Seis, em princípio, tenha sido influenciada por suas habilidades futebolistas. Para o autor:

Ao que tudo indica, diferentemente da maioria dos brasileiros, este imigrante sabia jogar futebol e, por isso, logo foi incorporado ao clube, aparecendo listado como sócio em junho daquele mesmo ano de 1904. Logo, Bochialini mudava-se, junto com suas duas irmãs e um cunhado, do Marco Seis para a Rua Estevam (ou Rua Ferrer) no 19, bem na estação de Bangu, e aparecia listado como "operário da fábrica de tecidos" (MOLINARI, 2015, p.165).

De fatb, a entrada do italiano na equipe arrabaldina não ficou circunscrita às quatros linhas do gramado. Curiosamente, César Bochialini conseguiu um emprego na Fábrica anos depois, deixando de lado qualquer empecilho que o impediria de compor o quadro de sócio da agremiação (O PAIZ, 27 mar., 1907).

Além do Bangu Athletic Club, conseguimos identificar a participação do jovem em outras associações da região. De acordo com o pedido de licença feito pela Sociedade Carnavalesca Flor da Lyra ao delegado de polícia, para sair às ruas no carnaval de 1906, Bochialini aparece como "fiscal zelador" da agremiação, ou seja, um indicativo importante na participação do italiano entre as principais atividades de lazer local (PEDIDO DE LICENÇA...,1906).

No entanto, um desdobramento importante envolveria César Bochialini. Depois de jogar 21 partidas pelo time titular do Bangu, entre 1904 e 1906, o jovem deixara de compor as escalações da equipe noticiadas em 1907 (MOLINARI, 2015). Supomos que o motivo tenha relação com a nota publicada na Gazeta de Notícias em 27 de março de 1907.

Há dias, entre Cesar Bochialini e seu cunhado Rittoni houve acesa discussão por ter o ultimo agredido a irmã solteira do outro, 
Entre os apitos do campo e da fábrica: o futebol à moda Bangu/Rio de Janeiro (1904-1929) Nei Jorge dos Santos Junior

na casa em que este e a moça residem.

Serenados os ânimos, continuaram os dois sem mais incidente a trabalhar na Fábrica de tecidos de Bangu, onde são empregados, mas no dia 23 houve nova desavença, mais violenta, pois os dois chegaram as vias de fato, esbofeteando-se.

Foi então que entrou uma celebre polícia em que se constituíram os homens de uma turma chamada da descarga, naquela fabrica, turma que toma a si dominar os outros companheiros. Quando Boccholine e Rottini brigavam no interior da sua casa, foi a habitação invadida pela turma da descarga e um e outro foram brutalmente espancados, saindo ambos feridos.

Já ali a ação da polícia se deveria fazer sentir eficaz, protegendo as vítimas dessa agressão, pois, embora, passíveis de castigo, pelo conflito em que se empenharam não era a particulares que competia aplicá-lo.

Houve mais, porém.

Os da turma de descarga prenderam os dois cunhados e os levaram à presença da autoridade da $3^{\circ}$ circunscrição em Campo Grande, sendo os dois, apesar de feridos e dos protestos que opuseram, recolhidos ao xadrez.

As duas moças, irmã e mulher do preso, foram ao delegado pedir por eles, regressando à casa tranquilas, por Ihes ter dito a autoridade que no dia seguinte estariam soltos ambos, visto que o fato não tinha importância.

A verdade, porém, é que, Bochialini ainda está na detenção e que no inquérito estão depondo os indivíduos que o agrediram e feriram (O PAIZ, 27 mar., 1907, p. 3).

Meses depois, o ex-jogador ganharia novamente as páginas policiais. Dessa vez, um novo elemento surgia para diminuir a pena de Bochialini, o juiz do caso, Raymundo Corrêa, desqualificou o delito cometido pelo trabalhador italiano de "ferimentos graves" para "ferimentos leves" (O PAIZ, 27 mar., 1907, p. 6).

César Bochialini, tendo tido uma questão com um cunhado seu, 
Entre os apitos do campo e da fábrica: o futebol à moda Bangu/Rio de Janeiro (1904-1929)

no Bangu, feriu-o com um canivete. Foi preso e o ferimento julgado grave, sendo Bochialini processado e denunciado por crime de ofensas graves.

Não foi, porém, feito exame de sanidade no ferido; e como a classificação do crime de ofensas físicas graves só se dá quando a cura demora-se por tempo maior de trinta dias ou quando o ferimento traz deformidade ao ofendido, a ausência desse elemento essencial nos autos, impedindo a caracterização do delito, fez com que o juiz Raymundo Correia desclassificasse, por sentença de ontem, o crime atribuindo a César Bochialini, de ferimentos graves, conforme era a denúncia, para ferimentos leves (O PAIZ, 27 mar., 1907, p. 6).

Consequentemente, os diretores da fábrica não incorporaram o jovem italiano ao trabalho, sendo demitido por mau comportamento. Os desdobramentos do caso exposto não poderiam seguir outro caminho: César Bochialini seria expulso do quadro de associados do clube. A exclusão se dava pela rigorosa proposta aprovada na primeira reunião pós-fundação, em 24 de abril de 1904, a mesma que impediria sócios que não fossem empregados da Fábrica. Para James Hartley, além da necessidade de ser "empregado da Companhia", como já havia exposto anteriormente, em caso de demissão "por mau comportamento", o sócio teria imediatamente seu nome excluído do quadro, "porém, se saísse por sua livre vontade, não havendo nada contra o seu caráter", poderia ter seu nome mantido entre os associados, mesmo não havendo mais vínculo com a fábrica (ATA DA SESSÃO... 24 abr., 1904). Vale destacar que o nome do italiano também desaparece entre os sócios da Flor da Lyra, tendo sua última aparição em 09 de fevereiro de 1907, isto é, um mês antes do ato de violência (O PAIZ, 9 fev., 1917).

A diligência no cotidiano fabril, como fora exposto, era considerada um fator de suma importância, sendo, aliás, um dos principais indicadores para a manutenção no quadro de sócios, embora, como argumenta Molinari (2015), deveria fazer parte dos 
Entre os apitos do campo e da fábrica: o futebol à moda Bangu/Rio de Janeiro (1904-1929) Nei Jorge dos Santos Junior

estatutos da agremiação. Todavia, o fato que nos chama a atenção é a clara demonstração da conexão dessas instituições, tendo a Companhia Progresso Industrial do Brazil como principal mediadora nessa relação.

De certa forma, no caso do Bangu, os motivos para essa relação estreita eram óbvios. A empresa subsidiava as atividades do clube; entre elas, cedendo um terreno de propriedade da fábrica para a instalação do campo de futebol e a construção da sede social ou, então, contribuindo para o pagamento de aluguéis. Além disso, a companhia oferecia ao clube uma quantia em dinheiro, a fim de complementar seu orçamento, que incluía despesas com conservação, limpeza da sede social e do campo, pagamento de impostos, energia elétrica, compra de uniformes ${ }^{2}$, transporte de jogadores e outras, por exemplo, o pedido feito em janeiro de 1906, em que o clube recorreria novamente ao Sr. João Ferrer, "pedindo auxílio para aumentar as arquibancadas e colocar no campo diversos jogos e exercícios atléticos para o divertimento dos sócios e seus familiares aos domingos e feriados" (ATA DA SESSÃO...19 jan. 1906).

Como uma espécie de extensão recreativa da fábrica, o clube representava uma continuidade do espaço do trabalho. A força dos operários e seu empenho na estruturação do Bangu se estendiam para além das questões trabalhistas, a partir do qual se mobilizavam e com o qual reiteradamente dialogavam.

Dessa forma, percebe-se que as instalações da agremiação se confundiam com as da companhia, compondo harmoniosamente um conjunto arquitetônico construído pela empresa no distante bairro fabril. Era normal, portanto, que a empresa oferecesse ao clube uma estrutura adequada para seu funcionamento, condicionando o clube como mais um departamento da empresa.

Após a reunião entre sócios, a solicitação de recursos era encaminhada ao Presidente Honorário do clube, cargo definido clara-

\footnotetext{
2 De acordo com a Ata de fundação, logo após a escolha das cores do uniforme, coube ao Sr. Stark, a missão de conseguir, junto ao Diretor da Fábrica, o pano necessário para fazer o fardamento do clube. Além disso, por diversas vezes, essa mesma atitude pode ser vista nas atas de reunião do clube.
} 
Entre os apitos do campo e da fábrica: o futebol à moda Bangu/Rio de Janeiro (1904-1929) Nei Jorge dos Santos Junior

mente no artigo sete de seus estatutos - "será conferido sempre o título de - Presidente Honorário - o Diretor Gerente da Companhia Progresso Industrial do Brasil, o qual será consultado em todas as resoluções tomadas pela diretoria, estranhas a estes estatutos" (ESTATUTOS DO BANGU...20 abr. 1913, p. 1-2). Isto é, o administrador gerente avaliava e designava os recursos necessários para o bom andamento do clube, em que suas ações interferiam diretamente na política do grêmio, principalmente no controle e na composição de seus quadros e dirigentes. Vale salientar que, qualquer obra ou evento realizado pelo clube, por ter sua sede no terreno da companhia, precisava de autorização prévia da fábrica, até mesmo jogos e torneios, como a disputa da Taça Ferrer, em que o administrador impôs o número de competidores, data e condição de participação: "só poderá tomar parte neste torneio, jogadores que são empregados da Cia. Progresso Industrial do Brasil" (ACTA DA SESSÃO...21 mar., 1911). No entanto, essa ligação, como vimos, não estava circunscrita ao clube de futebol. Os trabalhadores da fábrica Bangu foram, aliás, responsáveis pela criação de uma série de instituições, estando parte delas em funcionamento ainda hoje.

\section{Considerações finais}

Em Bangu, por mais que a condição de trabalho e moradia não seja intercambiável, mantendo cada um a sua especificidade, constatamos que a relação era muito próxima. Fosse ela tecida na fábrica ou no Bangu Athletic Club, esta aproximação - que não pode ser compreendida como invariável - possuía conexões complexas referente ao cotidiano fabril e, justamente por isso, o clube acabava configurando-se como local dinâmico de inter-relação e negociação entre vida de trabalho e vida urbana. Dessa forma, ainda que entremeados por relações de poder, a regular frequência de operários ou diretores nas ações da agremiação de futebol acabava aproximando a inclusão das necessidades cotidianas da população banguense que, ligados por relações de reciprocidade, 
Entre os apitos do campo e da fábrica: o futebol à moda Bangu/Rio de Janeiro (1904-1929) Nei Jorge dos Santos Junior

como aponta Thompson (2002), buscava o atendimento de suas demandas, o que não as isentariam de tensões.

Percebemos também que, a partir da organização do Bangu Athletic Club, novos códigos de pertencimento surgiram, juntamente com demandas sociais que contemplavam representação política e status social. Nesse sentido, o clube mostrou-se proficiente, pois, definido como entidade esportiva, isolado, portanto, diretamente do mundo do trabalho, trouxe em sua fundação e em seus primeiros tempos - e ainda hoje pela memória de seus sócios as marcas dos trabalhadores que tomaram a iniciativa de criar o clube e que ocuparam por décadas - como aconteceu em outras associações do bairro - cargos em sua direção, ao mesmo tempo em que trabalhavam na Companhia Progresso Industrial do Brasil. Acompanhar as mudanças pelas quais o clube passou a partir de suas atas, bem como a diversidade dos eventos que realizava, significa tentar captar flagrantes desses entroncamentos entre trabalho e lazer, sem hierarquizá-los, identificando nuances que se relacionam às trajetórias singulares dos sujeitos.

Isso posto, esperamos ter colaborado com a temática no sentido de propor um olhar além das diversões dos centros urbanos mais conhecidos da cidade do Rio de Janeiro. Além disso, intentamos explicitar que as "formas" e os "modelos" de compreensão do processo de consolidação do futebol sofreram ressignificações locais, os quais davam sentidos próprios conforme as suas estruturas intrínsecas.

\section{Referências}

ACTA DA SESSÃO da. Diretoria do Bangu Athletic Club. de 19 de janeiro de 1906.

ACTA DA SESSÃO da. Diretoria do Bangu Athletic Club. de 21 de março de 1911. 
Entre os apitos do campo e da fábrica: o futebol à moda Bangu/Rio de Janeiro (1904-1929) Nei Jorge dos Santos Junior

ATA DA SESSÃO da. Diretoria do Bangu Athletic Club de 24 de abril de 1904.

ATA DE FUNDAÇÃO. The Bangu Athletic Club, 1904.

ESTATUTOS do. Bangu Athletic Club, 20 de abril de 1913.

LEFEBVRE, H. De lo rural a lo urbano. 3.ed. Barcelona, Ediciones Península, 1975.

MALAIA, J. M. Revolução Vascaína: a profissionalização do futebol e inserção socioeconômica de negros e portugueses na cidade do Rio de Janeiro (1915-1934). 2010. 489f. Tese (Doutorado em História Econômica) - Departamento de História, Faculdade de Filosofia, Letras e Ciências Humanas da Universidade de São Paulo, São Paulo, 2010.

MELO, Victor Andrade; SANTOS JUNIOR, Nei Jorge dos. O esporte nos arrabaldes do Rio de Janeiro: o cricket em Bangu (1904-

1912). Movimento (ESEFID/UFRGS), v. 24, n. 3, p. 843-858, 2018.

MOLINARI, C. Mestres estrangeiros; operariado nacional:

resistências e derrotas no cotidiano da maior fábrica têxtil do rio de janeiro (1890 - 1920). 2015. 259 f., il. Dissertação (Mestrado em História) —o Universidade de Brasília, Brasília, 2015.

O PAIZ, Rio de Janeiro, 9 de fevereiro de 1917, p. 3.

O PAIZ, Rio de Janeiro, 27 de março de 1907, p. 3.

PEDIDO DE LICENÇA do Grupo Carnavalesco Flor da Lyra, 1906.

SANTOS JUNIOR, Nei Jorge dos e Melo, Victor Andrade de.

Violentos e desordeiros: representações de dois clubes do subúrbio na imprensa carioca (década de 10). Rev. bras. educ. fís. esporte [online]. v. 27, n. 3, p. 411-422, 2013.

SANTOS JUNIOR, Nei Jorge. A construção do sentimento local: o futebol nos arrabaldes de Andaraí e Bangu (1914-1923). 2012. 126f. Dissertação (Mestrado em História Comparada) - Instituto de História, Universidade Federal do Rio de Janeiro, Rio de Janeiro, 2012. 
Entre os apitos do campo e da fábrica: o futebol à moda Bangu/Rio de Janeiro (1904-1929) Nei Jorge dos Santos Junior

SANTOS JUNIOR, Nei Jorge. Um jogo de representações: o futebol suburbano nos jornais da cidade do Rio de Janeiro (década de 1910). Pensar prát., p. 1239-1255, 2013.

SANTOS JUNIOR, Nei Jorge. A vida divertida suburbana: representações, identidades e tensões em um arrabalde chamado Bangu (1895-1929). 2017. 230f. Tese (Doutorado em Estudos do Lazer) - Escola de Educação Física, Fisioterapia e Terapia Ocupacional, Universidade Federal de Minas Gerais, Belo Horizonte, 2017.

THOMPSON, E. P. A formação da classe operária inglesa III: a força dos trabalhadores. 3. ed. Rio de Janeiro: Paz e Terra, 2002.

\title{
Publisher
}

\begin{abstract}
Universidade Federal de Goiás. Faculdade de Educação Física e Dança. Publicação no Portal de Periódicos UFG. As ideias expressadas neste artigo são de responsabilidade de seus autores, não representando, necessariamente, a opinião dos editores ou da universidade.
\end{abstract}

